\title{
Mass Modeling of Common Medlar (Mespilus germanica) Fruit with Some Physical Characteristics
}

\author{
Ali Nejat Lorestani*, Sadegh Gawhari, Sajad Sadi \\ Mechanical Engineering of Agricultural Machinery Department, Faculty of Agriculture, Razi University, Kermanshah, I. R. Iran \\ *Corresponding Author: ali.lorestani@gmail.com
}

Copyright (C) 2014 Horizon Research Publishing All rights reserved.

\begin{abstract}
Fruits and vegetables with the similar weight and uniform shape are in high demand in terms of marketing value. Therefore, an awareness of grading fruits and vegetables based on weight is crucial. A part of this research was aimed to present some physical properties of Medlar fruit. In addition, in this study the mass of Medlar was predicted with using different physical characteristics in four models includes: Linear, Quadratic, S-curve, and Power. According to the results, all properties considered in the current study were found to be statistically significant at the $1 \%$ probability level and the best and the worst models for prediction the mass of Medlar were based on Volume and Length of the Medlar with determination coefficients of 0.996 and 0.580 , respectively. At last, mass model based on thickness from economical standpoint is recommended.
\end{abstract}

Keywords Mass, Modeling, Medlar, Physical Characteristics

\section{Introduction}

Mespilusgermanica, known as the common medlar is a large shrub or small tree, and the name of the fruit of this tree. Despite its Latin name, which means German or Germanic medlar, it is indigenous to southwest Asia and also southeastern Europe, mostly the Black Sea coasts of modern Turkey. It may have been cultivated for as long as 3000 years. Mespilusgermanica requires warm summers and mild winters and prefers sunny, dry locations and slightly acidic soil. Under ideal circumstances, the deciduous plant grows up to 8 metres $(26 \mathrm{ft})$ tall. Generally, it is shorter and more shrub-like than tree-like. With a lifespan of 30-50 years, M. germanica is rather short-lived. M. germanica leaves are dark green and elliptic, 8-15 centimetres (3.1-5.9 in) long and 3-4 centimetres (1.2-1.6 in) wide. The leaves turn red in autumn before falling.

The five-petaled white flowers, produced in late spring, are hermaphrodite, pollinated by bees, and self-fertile. The reddish-brown fruit is a pome, $2-3$ centimetres (0.79-1.2 in) diameter, with wide-spreading persistent sepals giving a 'hollow' appearance to the fruit. Mespilusgermanica was already being cultivated about three thousand years ago in the Caspian Sea region of northern Iran. It was introduced to Greece around 700 BC and to Rome about 200 BC.(available at http://en.wikipedia.org/wiki/Mespilus_germanica).

Agricultural crops and food products have several unique characteristics which set them different from engineering materials. These properties determine the quality of the fruit and identification of correlation among in these properties makes quality control easier (Janatizadeh et al., 2008). To design and optimization a machine for handling, cleaning, conveying and storing, the physical attributes and their relationships must be known. As an instance, grading of fruits by their size can be replaced with grading by their weight because it may be more economical. Grading fruit based on weight is important in packing and handling. In nearly all cases raw product grades are based on weight (O'Brian and Floyd, 1978). Size and shape determine how many fruit can be placed in containers of a given size. Volume and surface area could be beneficial in proper prediction drying rates and hence drying time in the dryer. On the other hand, volume and its relationship with packing coefficient are very important because having any information about Packing coefficient of fruits could result in efficient control of fruit quality during storage. Physical characteristics of agricultural products are the most important parameters to determine the proper standards of design of grading, conveying, processing and packaging systems (Tabatabaeefar and Rajabipour, 2005; Lorestani, et al., 2012).

Among these physical characteristics, mass, volume, projected area are the most important ones in determining sizing systems (Peleg and Ramraz, 1975). Many researches have been conducted to find physical properties of various types of agricultural products.

The regression analysis was used by Chuma et al. (1982) to develop equations for predicting volume and surface area. Determining relationships between mass and dimensions and projected areas may be useful and applicable (Stroshine, 1998; Marvin, et al., 1987). Tabatabaeefar and Rajabipour (2005) predicted apple mass through models that were based upon apple physical properties. Al-Maiman and Ahmad 
(2002) studied the physical properties of pomegranate and found models of predicting fruit mass while employing dimensions, volume and surface areas. Mass grading of fruit can reduce packaging and transportation costs, and also may provide an optimum packaging configuration (Peleg, 1985).

No detailed studies concerning mass modeling of Medlar fruit have yet been performed. The aims of this study were to determine the most suitable model for predicting Medlar fruit mass by its physical attributes and study some physical properties of Iranian Medlar to form an important database for other investigators or for sorting of Medlar.

\section{Materials and Methods}

The Medlar fruits were obtained from markets of Kermanshah in the west of Iran in March 2013. The 100 samples of the Medlars were tested in the Biophysical laboratory and Biological laboratory of Razi University of Kermanshah, Iran. The samples were weighted and dried in an oven at $105^{\circ} \mathrm{C}$ for $24 \mathrm{~h}$ (Lorestani, et al., 2012) and then weight loss on drying to final content weight was recorded as moisture content. The remaining material was kept in the desiccator until use. Medlar fruit mass (M) was determined with an electronic balance with $0.01 \mathrm{~g}$ sensitivity. To determine the average size of the samples, three linear dimensions namely as length(L), width(W) and thickness(T) were measured by using a digital caliper with $0.01 \mathrm{~mm}$ accuracy. Volume (V) was determined by the water displacement method (Mohsenin, 1986). The geometric mean diameter $(\mathrm{Dg})$ and surface areas $(\mathrm{S})$ were determined by using following formulas (Mohsenin, 1986), respectively:

$$
\begin{aligned}
D_{g} & =(L W T)^{1 / 3} \\
S & =\pi\left(D_{g}\right)^{2}
\end{aligned}
$$

Where: $\mathrm{L}$ is length of Medlar (mm), W is width of Medlar $(\mathrm{mm})$; $\mathrm{T}$ is thickness of Medlar $(\mathrm{mm}), \mathrm{S}$ is surface area $\left(\mathrm{mm}^{2}\right)$ and Dg is geometric mean diameter $(\mathrm{mm})$. Then, projected areas (PA1, PA2 and PA3) in three perpendicular directions of the Medlar were measured by a $\Delta \mathrm{T}$ area-meter, MK2 model device with $0.1 \mathrm{~cm}^{2}$ accuracy (DELTA-T Device Ltd., Cambridge, UK). And criteria projected area (CPA) is defined as follow (Mohsenin, 1986):

$$
C P A=\left(P A_{1}+P A_{2}+P A_{3}\right) / 3
$$

Where PA1, PA2 and PA3 are first, second and third projected area $\left(\mathrm{mm}^{2}\right)$. In order to estimate mass models of Medlars, the following models were considered:

1. Single variable regression of Medlar mass based on Medlar dimensional characteristics: length (L), width $(\mathrm{W})$, thickness $(\mathrm{T})$, and geometric mean diameter (Dg).

2. Single variable regressions of Medlar mass based on Medlar projected areas and criteria projected area.

3. Single variable regression of Medlar mass based on measured volume.
4. Single variable regression of Medlar mass based on surface area.

In all cases, the results which were obtained from experiments were fitted to Linear, Quadratic, S-curve, and Power models which are presented as following equations, respectively:

$$
\begin{gathered}
M=b_{0}+b_{1} X \\
M=b_{0}+b_{1} X+b_{2} X^{2} \\
\operatorname{Ln}(M)=b_{0}+b_{1} / X \\
M=b_{0} X^{b_{1}}
\end{gathered}
$$

Where $\mathrm{M}$ is mass (g), $\mathrm{X}$ is the value of a parameter that we want to find its relationship with mass (in depended parameter), b0, b1, and b2 are curve fitting parameters which are different in each equation.

One evaluation of the goodness of fit is the value of the coefficient of determination. For regression equations in general, the nearer $\mathrm{R} 2$ is to 1.00 , the better the fit (Stroshine, 1998). SPSS 19 software (SPSS, Inc, Chicago, IL, USA) was used to analyze data and determine regression models among the physical attributes.

\section{Results and Discussion}

A summary of the physical properties of Medlar is shown in Table1.These properties were found at specific moisture contents about $27.13 \%$ wet basis. As seen in Table 1, all properties which were considered in the current study were found to be statistically significant at $1 \%$ probability level. According to the results, the mean values of properties which were studied in this research (length, width, thickness, geometric mean diameter, Volume, surface area, mass and projected areas) are $26.11 \mathrm{~mm}, 19.96 \mathrm{~mm}, 19.75 \mathrm{~mm}, 21.71$ $\mathrm{mm}, 6.36 \mathrm{~cm} 3,1503.40 \mathrm{~mm} 2,6.51 \mathrm{~g}, 30.36 \mathrm{~mm} 2,38.35$ $\mathrm{mm} 2$ and $37.81 \mathrm{~mm} 2$, respectively.

Mass models and coefficient of determination $\left(\mathrm{R}^{2}\right)$ that obtained from the data for Medlars are shown in table 2. All of the models coefficients were analyzed with F-test and t-test in SPSS 19 Software, where, all of them were significant at $\alpha=1 \%$.

Nonlinear models were used only for comparison with linear regression models.

For mass modeling based on dimensional characteristic including length, width and thickness, the best model was Linear with $\mathrm{R} 2=0.892$ :

$$
M=-8.739+0.772 T R^{2}=0.892
$$

Whereas this model can predict the relationships between the mass with length and width with R2 of 0.580 and 0.877 , respectively.

For prediction of the mass of Medlar based on volume the best model was Quadratic with R2 $=0.996$.

$$
M=0.000-0.016 V+1.036 V^{2} R^{2}=0.996
$$

According to the results, for prediction of the mass of the Medlar based on geometric mean diameter, Power model 
were the best model with $\mathrm{R} 2=0.953$.

$$
\text { Powermodelis } M=0.001 D_{g}^{2.749} R^{2}=0.953
$$

This model is not economical because for calculating the geometric mean diameter $(\mathrm{Dg})$ we must measure three dimensions of Medlars and it is time consuming and costly.

For mass modeling of Medlar based on projected areas including PA1, PA2, PA3 and CPA, the best model was Quadratic with R2 $=0.984$.

$$
M=-1.605+0.133 C P A+0.003 C P A^{2} R^{2}=0.984
$$

For prediction of the mass of the Medlar based on surface area the best model was Power with $\mathrm{R} 2=0.953$.

$$
M=0.000 S^{1.375} R^{2}=0.953
$$

Tabatabaeefar and Rajabipour, (2005), determined a total of 11 regression models in the three different categories for two different varieties of apple fruits.

According to the results the Power and Quadratic models could predict the relationships among the mass and some physical properties of Medlar with proper value for determination coefficient.

\section{Conclusions}

Some physical properties and their relationships of mass of Medlar are presented in this study. From this study it can be concluded that:

1. All properties considered in the current study were found to be statistically significant at the $1 \%$ probability level.

2. The best model for prediction the mass of Medlar among the dimensional models was Linear as: $M=-8.739+0.772 T, R^{2}=0.892$

3. The best model for prediction the mass of Medlar was based on second projected area which perpendicular to
W direction of Medlar and it was Power form as $M=0.010 P A_{2}^{1.756}, R^{2}=0.961$, and the worst was based on third projected area of Medlar and it was Quadratic form as $\mathrm{M}=2.494-0.090 P A_{3}+$ $0.005 P A_{3}^{2}, R^{2}=0.922$.

4. At last, mass model based on thickness from economical standpoint is recommended.

This information can be used in the design and development of sizing mechanisms and other post harvest processing machines. At the end, it is recommended that other properties of Medlar such as thermal, rheological, mechanical, and nutritional characteristics are to be studied and changes of these properties are to be examined as a function of moisture content and ripening phases.

Table 1. Some physical properties of Medlar.

\begin{tabular}{|c|c|c|c|c|}
\hline \multirow{2}{*}{ Properties } & \multicolumn{3}{|c|}{ Medlar } & \multirow{2}{*}{$\begin{array}{c}\text { Significant } \\
\text { level }\end{array}$} \\
\cline { 2 - 4 } & Max & Min & Average & $* *$ \\
\hline L (mm) & 34.96 & 19.56 & 26.11 & $* *$ \\
\hline W (mm) & 26.53 & 14.92 & 19.96 & $* *$ \\
\hline T (mm) & 27.71 & 14.50 & 19.75 & $* *$ \\
\hline M (g) & 12.61 & 2.65 & 6.51 & $* *$ \\
\hline V (ml) & 12.32 & 2.62 & 6.36 & $* *$ \\
\hline Dg (mm) & 28.08 & 16.17 & 21.71 & $* *$ \\
\hline S (mm2) & 2477.01 & 821.90 & 1503.40 & $* *$ \\
\hline PA1 (mm2) & 46.2 & 15.1 & 30.36 & $* *$ \\
\hline PA2 (mm2) & 59.8 & 24.1 & 38.36 & $* *$ \\
\hline PA3 (mm2) & 54.5 & 24.2 & 37.81 & $* *$ \\
\hline CPA (mm2) & 53.03 & 22.87 & 35.51 & $* *$ \\
\hline SPH (\%) & 98.95 & 68.79 & 83.47 & $* 4$ \\
\hline
\end{tabular}

${ }^{* *} \mathrm{P}<0.01$

Table 2. The best models and their constant values for mass based on the selected attributes forMedlar

\begin{tabular}{|c|c|c|c|c|c|c|}
\hline \multirow{2}{*}{ Dependent Parameter } & \multirow{2}{*}{ Independent Parameters } & \multirow{2}{*}{ The best model } & \multicolumn{3}{|c|}{ Constant Values } & \multirow{2}{*}{$\mathrm{R}^{2}$} \\
\cline { 5 - 6 } & & & $\mathrm{b}_{0}$ & $\mathrm{~b}_{1}$ & $\mathrm{~b}_{2}$ & \\
\hline $\mathrm{M}(\mathrm{g})$ & $\mathrm{L}(\mathrm{mm})$ & $\mathrm{S}$ curve & 3.817 & -51.381 & - & 0.580 \\
\hline $\mathrm{M}(\mathrm{g})$ & $\mathrm{W}(\mathrm{mm})$ & $\mathrm{S}$ curve & 4.152 & -45.760 & - & 0.877 \\
\hline $\mathrm{M}(\mathrm{g})$ & $\mathrm{T}(\mathrm{mm})$ & Linear & -8.739 & 0.772 & - & 0.892 \\
\hline $\mathrm{M}(\mathrm{g})$ & $\mathrm{V}(\mathrm{ml})$ & Quadratic & 0.000 & -0.016 & 1.036 & 0.996 \\
\hline $\mathrm{M}(\mathrm{g})$ & $\mathrm{D}_{\mathrm{g}}(\mathrm{mm})$ & Power & 0.001 & 2.749 & - & 0.953 \\
\hline $\mathrm{M}(\mathrm{g})$ & $\mathrm{S}\left(\mathrm{mm}^{2}\right)$ & Power & 0.000 & 1.375 & - & 0.953 \\
\hline $\mathrm{M}(\mathrm{g})$ & $\mathrm{PA}_{1}\left(\mathrm{~mm}^{2}\right)$ & Quadratic & 1.053 & 0.023 & 0.005 & 0.936 \\
\hline $\mathrm{M}(\mathrm{g})$ & $\mathrm{PA}_{2}\left(\mathrm{~mm}^{2}\right)$ & Power & 0.010 & 1.756 & - & 0.961 \\
\hline $\mathrm{M}(\mathrm{g})$ & $\mathrm{PA}_{3}\left(\mathrm{~mm}^{2}\right)$ & Quadratic & 2.494 & -0.090 & 0.005 & 0.922 \\
\hline $\mathrm{M}(\mathrm{g})$ & ${\mathrm{CPA}\left(\mathrm{mm}^{2}\right)}$ & Quadratic & -1.605 & 0.133 & 0.003 & 0.984 \\
\hline
\end{tabular}




\section{Acknowledgements}

The authors would like to express their gratitude and their sincere appreciation to the Deputy of Agronomy Departments for their cooperation and laboratory support at the Razi University of Kermanshah.

\section{REFERENCES}

[1] http://en.wikipedia.org/wiki/Mespilus_germanica. (accessed at: $01 / 06 / 2013$ )

[2] Janatizadeh A, Naderi-Boldaji M, Fatahi R, GhasemiVarnamkhasti, M, Tbatabaeefar, A. 2008. Some Post harvest Physical Properties of Iranian apricot fruit. Int. agrophysics. 22: 356-363.

[3] O'Brian M, Floyd S. 1978. A micro computer controlled weighing and print out system for fruit and vegetable grading. Transaction of ASAE. 16: 446-450.

[4] Tabatabaeefar A, Rajabipour A. 2005. Modeling the mass of apples by geometrical attributes. Sci. Hort., 105: 373-382.

[5] Lorestani AN, Jaliliantabar F, Gholami R. 2012. Mass modeling of caper (Capparisspinosa) with some engineering properties. Quality Assurance and Safety of Crops \& Foods, 4: e38-e42.

[6] Peleg K, Ramraz Y. 1975. Optimal sizing of citrus fruit. Trans. ASAE. 18 (6): 1035-1039.

[7] Chuma Y, Uchida S, Shemsanga HH. 1982. Simultaneous measurement of size, surface area and volume of grains and soybean. Transaction of the ASAE 25(6): 1752-1756.

[8] Stroshine R. 1998. Physical Properties of Agricultural Materials and Food Products. Course manual. Purdue Univ. USA.

[9] Marvin JP, Hyde GM, Cavalieri RP. 1987. Modeling potato tuber mass with tuber dimensions. Transactions of the ASAE 30: 1154-1159.

[10] Al-Maiman S, Ahmad D. 2002. Changes in physical and chemical properties during pomegranate (Punicagranatum L.) fruit maturation. J. Food Chem., 76(4): 437-441.

[11] Peleg K. 1985. Produce Handling, Packaging and Distribution. The AVI Publishing Company. Inc. Westport, Connecticut, pp. 20-90.

[12] Mohsenin NN. 1986. Physical properties of Plant and Animal Materials. Second revised. Gordon and Breach Sci. Publ., New York. 